\title{
Reconstruction of Head and Neck Mucormycosis: A Literature Review and Own Experience in Immediate Reconstruction
}

\author{
Julio Juarez Palacios, MD ${ }^{1}$ Erik Viana Hanson, MD $^{2}$ \\ Raúl-Saldaña López Infante, MD ${ }^{4}$ \\ ${ }^{1}$ Department of Plastic and Reconstructive Surgery, Hospital Regional \\ de Alta Especialidad de Ixtapaluca, Estado de México, Mexico \\ 2 Department of Surgery, Hospital General de Mexico "Dr. Eduardo \\ Liceaga," Ciudad de México, Mexico \\ ${ }^{3}$ Department of Surgery, Hospital Regional de Alta Especialidad de \\ Ixtapaluca, Estado de México, Mexico \\ ${ }^{4}$ Department of Plastic and Reconstructive Surgery, Hospital Ángeles \\ Lomas, Ciudad de México, Mexico
}

J Reconstr Microsurg Open 2019;4:e65-e72.

\author{
Marco Aurelio Medina Rendon, MD $^{3}$
}

Address for correspondence Erik Hanson-Viana, MD, Hospital General de México “Dr. Eduardo Liceaga” Doctor Balmis No. 148, Colonia Doctores, Delegación Cuauhtémoc, C.P. 06726, Ciudad de México, México (e-mail: erikhv@hotmail.com).

\begin{abstract}
Keywords

- mucormycosis reconstruction

- zygomycosis reconstruction

- mucormycosis flap

Background Mucormycosis is a rare invasive and fatal fungal infection. A prompt diagnosis is the most critical aspect for an improved patient outcome. Along with antifungal therapy, radical surgical debridement must be done expeditiously to eradicate this fungus. In this article, we evaluated the feasibility of immediate reconstruction after surgical debridement.

Methods A retrospective study was performed at Hospital Regional de Alta Especialidad de Ixtapaluca, Estado de México, Mexico, between June 2017 and June 2018. Five patients, three males and two females, with a mean age of 39 years were presented in addition to a literature review based on MEDLINE, Google Scholar, PubMed Central, and Embase platforms until june 2018.

Results From our presented series, all five flaps survived and showed no evidence of mucormycosis recurrence or flap loss. In the literature review, we collected 16 cases from 14 different publications of individuals with head and neck mucormycosis. Reconstruction was made with a free (12 cases) or pedicled flap (four cases). Eleven males and five females with a mean patient age of 33.0 years were studied. Only two authors described an early or immediate reconstruction. The average time of the delayed reconstruction after surgical debridement was 16.7 weeks.

Conclusion After aggressive surgical resection, immediate reconstruction can be done safely based on clinical criteria and as long as there is no evidence of hyphae invasion on wound edges in the intraoperative pathology examination.
\end{abstract}

Mucormycosis is a rare ( 0.43 to 1.7 cases per million per year $)^{1}$ invasive fungal infection caused by various opportunistic fungi of the Mucoraceae family. Eighty percent of these infections are caused by Rhizopus, Mucor, and Lichtheimia and usually affect poorly controlled diabetic patients (36\%), followed by patients with malignancy (17\%), and solid organ transplantation (7\%)

received

October 13, 2018

accepted after revision

March 18, 2019

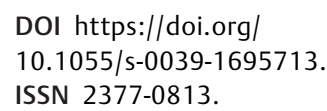

among others. ${ }^{2}$ However, in developing countries, diabetes incidence could be much more common $(>80 \%$ ) than found in other parts of the world.

Mucormycosis was considered fatal until the 1960's when amphotericin was introduced as a treatment. Thirty years later, encapsulated liposomes enhanced intracellular

Copyright $\odot 2019$ by Thieme Medical Publishers, Inc., 333 Seventh Avenue, New York, NY 10001, USA.

License terms Tel: +1(212) 584-4662.

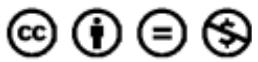


amphotericin delivery, thus decreasing the renal toxicity and increasing the therapeutic index by more than 20 -fold. ${ }^{3}$ Today, the reported mortality is 50 to $90 \%$ depending on the disease form. ${ }^{2}$

In this study, we present 16 patients who underwent reconstruction after head and neck mucormycosis in addition to our personal experience with four immediate and one late reconstruction.

\section{Methods}

Our reported case series was conducted as a retrospective study at Hospital Regional de Alta Especialidad de Ixtapaluca, Estado de México, Mexico. Five patients, consisting of three males and two females with a mean age of 39 years (range, 17-51 years) who presented with infections between June 2017 and June 2018 (-Table 1) are described. The etiological cause of the mucormycosis was diabetes mellitus in four patients and trauma in one; all of them underwent reconstruction using free (four-fifths) or pedicle (one-fifth) flaps. The study was retrospective and, therefore, did not require approval from the ethics committee. The medical charts were reviewed to obtain the following data: (1) age, (2) sex, (3) localization, (4) comorbidities, (5) medical treatment, (6) surgical resection, (7) flap type, and (8) time from debridement surgery to reconstruction.

\section{Operative Technique}

Once an infection is diagnosed, parenteral antifungal therapy was initiated with liposomal amphotericin B (L-AmB), and a contrast computed tomography (CT) scan was requested for surgical planning. The volume and size needed for the reconstruction were calculated to choose an adequate flap for reconstruction. The flap type was selected depending on the CT scan or the magnetic resonance image (MRI) findings and by calculating the possible volume and flap size. If more volume was required, a chimeric flap was planned. The resection was assessed by a multidisciplinary team (oncological, maxillofacial, and plastic surgeons). A two-team approach was used thus reducing the time of surgery and wound contamination in the donor area. The skin and soft tissue were resected with a $1-\mathrm{cm}$ margin of macroscopic healthy tissue in addition to a complete resection from all of the affected bone.

Meanwhile, flap elevation started by raising one of the flap's borders to find the primary perforator and start of the pedicle dissection until the desired length was reached. All resected specimens were then sent to the pathologist for positive border evaluation. The samples were examined after hematoxylin and eosin staining (20-30 minutes) for rapid hyphae evaluation (-Fig. 1). The definitive biopsies were evaluated after staining with Grocott's methenamine silver. After the intraoperative analysis, with no apparent affected tissue left, we selected the recipient vessels, while considering flap colocation, and pedicle length. After dissection, we sent 1 to $2 \mathrm{~mm}$ of the distal portion from the recipient artery and vein for hyphae analysis according to the previously described procedure. When no signs of invasion were confirmed and all apparent macro and microscopically affected tissues were debrided, the pedicle was freed and anastomosis performed. After surgery, all patients were admitted to the intensive care unit for surveillance. If the patient had a satisfactory response after at least 3 weeks of L-AmB, the parenteral antifungal was switched to oral posaconazole.

Table 1 Present case series of reconstruction in head and neck mucormycosis

\begin{tabular}{|l|l|l|l|l|}
\hline Case & $\begin{array}{l}\text { Sex/age } \\
(\mathrm{y})\end{array}$ & Etiology & Surgical resection and reconstruction & Outcome \\
\hline 1 & F/41 & $\begin{array}{l}\text { DM2, } \\
\text { ARF, } \\
\text { MOF }\end{array}$ & $\begin{array}{l}\text { Left orbital exenteration, resection of the submandibular gland, } \\
\text { left facial muscles. Reconstructed with a free } 22 \mathrm{~cm} \times 16 \mathrm{~cm} \text { ALT } \\
\text { flap, anastomosed to the superior thyroid artery }\end{array}$ & $\begin{array}{l}\text { Flap without complica- } \\
\text { tions, patient deceased } \\
\text { after } 10 \text { days }\end{array}$ \\
\hline 2 & M/42 & Trauma & $\begin{array}{l}\text { Right orbital exenteration and frontotemporal craniectomy. } \\
\text { Reconstructed with a frontal flap and a second stage methyl } \\
\text { methacrylate cranial prosthesis }\end{array}$ & $\begin{array}{l}\text { Flap survival and asymp- } \\
\text { tomatic. With a 1-year } \\
\text { follow-up }\end{array}$ \\
\hline 3 & M/51 & $\begin{array}{l}\text { Smoker, } \\
\text { DM2, } \\
\text { ARF, SAH }\end{array}$ & $\begin{array}{l}\text { Left hemifacial skin resection, left orbital exenteration and total } \\
\text { maxillectomy. Reconstructed with a free } 18 \text { cm } \times 12 \text { cm ALT flap, } \\
\text { anastomosed to the facial artery }\end{array}$ & $\begin{array}{l}\text { Flap survival and asymp- } \\
\text { tomatic. With 5 months } \\
\text { of follow-up }\end{array}$ \\
\hline 4 & F/17 & DM2 & $\begin{array}{l}\text { Right orbital exenteration }+ \text { left total maxillectomy. Recon- } \\
\text { structed with a free 12 cm } \times 7 \text { cm MSAP flap, anastomosed to the } \\
\text { facial artery }\end{array}$ & $\begin{array}{l}\text { Flap survival and asymp- } \\
\text { tomatic. With } 3 \text { months } \\
\text { of follow-up }\end{array}$ \\
\hline 5 & M/46 & DM2 & $\begin{array}{l}\text { Left orbital exenteration, left total and right infrastructure } \\
\text { maxillectomy, partial ethmoidectomy and sphenoidectomy. } \\
\text { Reconstructed with a free chimeric } 20 \mathrm{~cm} \times 10 \text { cm ALT-VL flap, } \\
\text { anastomosed to the temporal artery }\end{array}$ & $\begin{array}{l}\text { Flap survival after } \\
2 \text { weeks, no follow-up }\end{array}$ \\
\hline
\end{tabular}

Abbreviations: ALT, anterolateral thigh; ARF, acute renal failure; DM2, diabetes mellitus type 2; F, female; M, male; MOF, multi organic failure; MSAP, medial sural artery perforator; SAH, systemic arterial hypertension; VL, vastus lateralis.

${ }^{a}$ Deceased secondary to intra-hospitalary pneumonia.

${ }^{\mathrm{b}}$ Reconstructed 5 weeks after surgery due to presenting hypha invasion in the vein wall (-Fig. 1).

'Patient was discharged by his own will and did not presented for follow-up. 


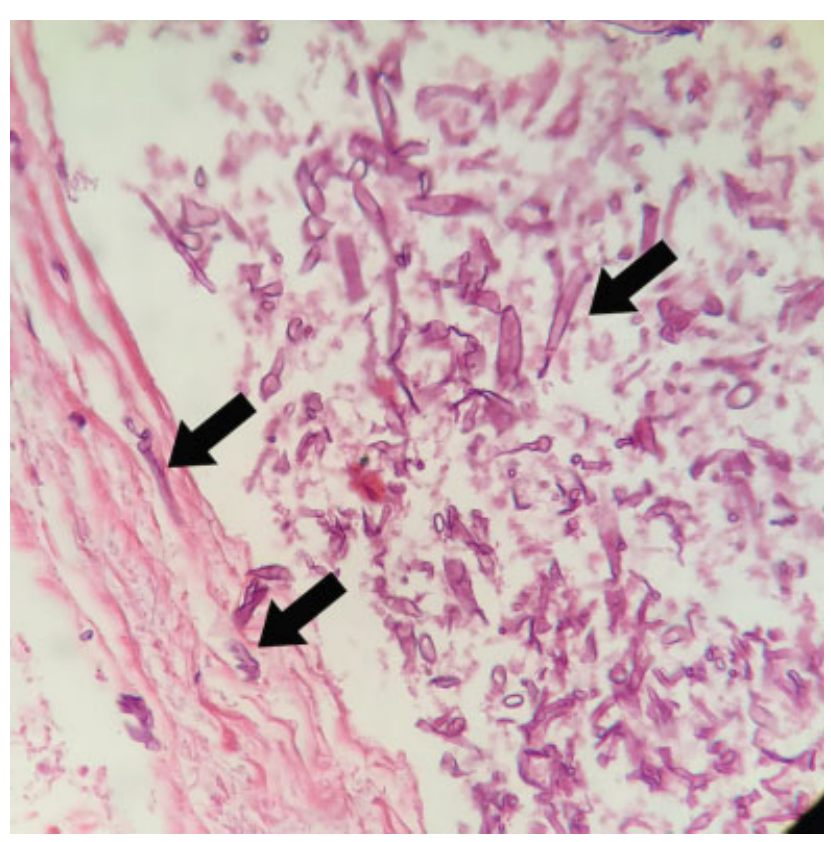

Fig. 1 A transverse cut of the temporal vein, treated with hematoxylin and eosin stain, thus presenting extensive wall fibrosis. The presence of broken hyphae invasion in the vein wall can be observed (black arrow).

\section{Search Strategy}

The search was done using MEDLINE, Google Scholar, PubMed Central, and Embase databases using the following English language keywords combined with Boolean logical operators: ("Mucormycosis Reconstruction" or "Zygomycosis Reconstruction" or "Mucormycosis Flap" or "Rhino-Orbital infection Reconstruction" [title/abstract/medical subject headings (MeSH) terms]). There were no limits on the search; only articles written in English were selected. Duplicates occurring in the different databases were removed. From the search, publications were ordered by date (from December 1, 1988 to June 1,2018 ). A total of 154 articles were chosen by their title (containing the above-mentioned keywords), and 134 articles were excluded based on the information in the abstract (by not being reconstruction cases in mucormycosis patients) and from those remaining 20 articles, five publications were excluded due to the lack of head and neck reconstruction. One other publication was excluded for insufficient patient information. The references of the selected articles were also examined for possible additional relevant articles. In summary, a total of 16 patients from 14 different publications were collected (-Table 2). Studies identified through the electronic and manual searches were listed with key information using Microsoft Excel 2011 (Microsoft Corp., Redmond, WA).

\section{Inclusion and Exclusion Criteria}

From all of the selected original articles, we analyzed those patients who underwent reconstructive surgery with a free or pedicle flap after surgical resection due to head- and neckrelated mucormycosis infections. Observational studies were included (retrospective and prospective) in addition to case reports. Articles containing data from other studies or duplicate studies were excluded in addition to review articles, technical descriptions, discussions, commentaries, editorials, and letters. For articles presented by the same author, we verified that data were not identical; if identical data or if any doubt existed, the data were excluded. Data were extracted independently by two researchers (EH and MAR), and disagreements were resolved by consensus with the senior author (JP). The collected data included the author, publication date, study location, patient age, sex, localization, comorbidities, medical treatment, surgical resection, postsurgical complications, reconstruction and flap types, and reconstruction and follow-up times.

\section{Results}

Five reconstruction cases in patients with head and neck mucormycosis were presented (-Table 1 ); from those, four rhinocerebral and one cutaneous (case 1) infection were observed. All of them were treated with L-AmB. Reconstruction was done immediately after surgical resection and debridement in four cases, and in one case, we did a secondary reconstruction 5 weeks after surgical treatment. In one patient (case 2), two debridement surgeries were done. Initially this patient had a craniectomy and 2 weeks later, a right orbital exenteration and immediate reconstruction with a frontal flap was done. A second reconstruction was done for the methyl methacrylate cranial prosthesis insertion. In all five flaps, no complications were presented although one of our patients (case 1 ) died on the 10th day postoperatively due to nosocomial pneumonia, showing no signs of mucormycosis recurrence, flap loss (-Fig. 2), or adverse cerebral effects.

Case 4: A 17-year-old female with a 1-year history of diabetes was admitted for an oronasal fistula (-Fig. 3A), signs of chronic sinusitis, and periocular edema. L-AmB was initiated due to a high suspicion of mucormycosis. After a week of antifungal treatment, the patient presented with blurry vision. Thus, a mucosal biopsy of the right sinus was taken and finding Rhizopus sp. was detected. The CT scan showed eye and ocular muscle involvement. Thus, a right-orbital exenteration and total maxillectomy were done. Intraoperative analysis from the resected tissue margins was reported as negative. Although hyphae invasion was reported in the temporal receptor vein wall (-Fig. 1), delayed reconstruction was chosen and the wound was covered with Acticoat (Smith \& Nephew, Hull, UK). Postoperatively, the patient presented with a nasoorbital and oroantral fistulas (-Fig. 3B) and continued with antifungal therapy for 5 weeks, additionally, until reconstructive surgery was done. For surgical planning, we made a stereolithography model and repeated the CT scan with bone reconstruction to analyze the extent of the bone defect and the localization of the fistulas. A $12 \mathrm{~cm} \times 7 \mathrm{~cm}$ medial sural artery perforator flap was anastomosed to the facial artery, covering the nasoorbital and oroantral fistula. The patient continues to be asymptomatic with no evidence of fistula or mucormycosis up to the 2-month follow-up (-Fig. 3C).

Case 5: A 46-year-old male with undiagnosed diabetes, was admitted after 1 week of progressive eye pain and redness, progressed with fever, and presented with hard palate necrotic 
Table 2 All published cases of reconstruction in head and neck mucormycosis

\begin{tabular}{|c|c|c|c|c|c|}
\hline Author (year) & $\begin{array}{l}\text { Age } \\
\text { (y)/sex }\end{array}$ & Etiology & Surgical treatment & Type of reconstruction & $\begin{array}{l}\text { Time of } \\
\text { reconstruction }\end{array}$ \\
\hline $\begin{array}{l}\text { Alleyne et al } \\
(1999)^{4}\end{array}$ & $24 / \mathrm{M}$ & DM2 & $\begin{array}{l}\text { Three interventions: right total } \\
\text { maxillectomy, right orbital exenteration, } \\
\text { and dissection of the trigeminal nerve }\end{array}$ & Temporalis muscle flap & Late \\
\hline $\begin{array}{l}\text { Lari et al } \\
(2002)^{5}\end{array}$ & $35 / F$ & DM2 & $\begin{array}{l}\text { Left orbital exenteration and left external } \\
\text { ethmoidectomy }\end{array}$ & $\begin{array}{l}\text { Galeal frontalis- } \\
\text { pericranial flap }\end{array}$ & $3 \mathrm{mo}$ \\
\hline $\begin{array}{l}\text { Shand et al } \\
(2004)^{15}\end{array}$ & $27 / \mathrm{M}$ & Trauma & $\begin{array}{l}\text { Eight interventions: debridement, left } \\
\text { orbital exenteration, left suprastructure } \\
\text { maxillectomy }\end{array}$ & RFFF & $52 \mathrm{~d}$ \\
\hline $\begin{array}{l}\text { Tidwell } \\
\text { et al }(2005)^{6}\end{array}$ & $1.5 / \mathrm{F}$ & Trauma & $\begin{array}{l}\text { Four interventions: skin and soft tissue } \\
\text { debridements }\end{array}$ & $\begin{array}{l}\text { Pre-expanded } \\
\text { cervicofacial flap }\end{array}$ & $2 w k$ \\
\hline \multirow[t]{2}{*}{$\begin{array}{l}\text { Adler et al } \\
(2008)^{8}\end{array}$} & $45 / M$ & DM2 & $\begin{array}{l}\text { Three interventions: Left orbital } \\
\text { exenteration, left total maxillectomy, } \\
\text { sphenoidectomy, and ethmoidectomy }\end{array}$ & $\begin{array}{l}\text { LFCP chimeric free flap } \\
\text { with VL }\end{array}$ & Immediate \\
\hline & $41 / \mathrm{M}$ & Trauma & $\begin{array}{l}\text { Scalp and a } 10 \times 10 \mathrm{~cm} \text { cranial bone } \\
\text { resection }\end{array}$ & LDFF +7 th rib & Early \\
\hline $\begin{array}{l}\text { Odessey } \\
\text { et al }(2008)^{13}\end{array}$ & $64 / M$ & DM2 & $\begin{array}{l}\text { Right subtotal maxillectomy, right lateral } \\
\text { nasal wall, and hard palate resection }\end{array}$ & $\begin{array}{l}\text { Free VRAM with three } \\
\text { debulking procedures }\end{array}$ & $4 \mathrm{mo}$ \\
\hline $\begin{array}{l}\text { Antonetti } \\
\text { et al }(2009)^{14}\end{array}$ & $10 / \mathrm{M}$ & Burn & Mandibular resection and debridement & Free FOCF & $10 \mathrm{mo}$ \\
\hline $\begin{array}{l}\text { Ojeda-Uribe } \\
\text { et al }(2010)^{16}\end{array}$ & $55 / F$ & DM2 & $\begin{array}{l}\text { Debridement of lower lip and chin, } \\
\text { mandibular and floor of the mouth } \\
\text { resection with partial glossectomy }\end{array}$ & $\begin{array}{l}\text { Mandibular porous } \\
\text { titanium prosthesis } \\
\text { and LDFF }\end{array}$ & Late \\
\hline $\begin{array}{l}\text { Metzen } \\
\text { et al }(2012)^{9}\end{array}$ & $63 / \mathrm{F}$ & MDS & Right infrastructure maxillectomy & SOFF & Immediate \\
\hline $\begin{array}{l}\text { Herford } \\
\text { et al }(2013)^{7}\end{array}$ & $13 / \mathrm{M}$ & MDS & Anterior maxillectomy & $\begin{array}{l}\text { LeFort I advancement } \\
\text { and a two-stage tong } \\
\text { flap }\end{array}$ & Late \\
\hline $\begin{array}{l}\text { Murphy } \\
\text { et al }(2013)^{17}\end{array}$ & $68 / \mathrm{M}$ & MDS & $\begin{array}{l}\text { Right orbital exenteration, resection of } \\
\text { frontal, maxillary and ethmoidal sinuses, } \\
\text { and inferior and middle turbinates }\end{array}$ & Chimeric ALT-VL flap & $2 \mathrm{wk}$ \\
\hline $\begin{array}{l}\text { Silberstein } \\
\text { et al }(2014)^{10}\end{array}$ & $41 / \mathrm{F}$ & DM2 & $\begin{array}{l}\text { Two interventions: left orbital exentera- } \\
\text { tion, left subtotal maxillectomy, bilateral } \\
\text { ethmoidectomy, sphenoidectomy, partial } \\
\text { rhinectomy, and right maxillary sinus } \\
\text { antrostomy }\end{array}$ & $\begin{array}{l}\text { Free TRAM + FTSG, and } \\
\text { an STSG in a second } \\
\text { stage }\end{array}$ & $2 \mathrm{mo}$ \\
\hline $\begin{array}{l}\text { Bhatnagar } \\
\text { and Agarwal } \\
(2016)^{12}\end{array}$ & $35 / M$ & - & $\begin{array}{l}\text { Right type IV orbital exenteration and } \\
\text { medial orbital wall resection }\end{array}$ & RFFF & $6 \mathrm{mo}$ \\
\hline \multirow[t]{2}{*}{$\begin{array}{l}\text { Augustine } \\
\text { et al }(2017)^{11}\end{array}$} & $2 / \mathrm{M}$ & MDS & $\begin{array}{l}\text { Left total maxillectomy, resection of the } \\
\text { hard palate, nasal septum and left ethmoid } \\
\text { sinus }\end{array}$ & Free FOCF + nasal strut & - \\
\hline & $4.5 / \mathrm{M}$ & MDS & $\begin{array}{l}\text { Four interventions: type II orbital } \\
\text { exenteration, resection of facial muscles, } \\
\text { external ethmoidectomy, nasal and } \\
\text { Caldwell-Luc resection }\end{array}$ & VIOF with 2 skin pads & $8 \mathrm{mo}$ \\
\hline
\end{tabular}

Abbreviations: ALT, anterolateral thigh; ARF, acute renal failure; DM2, diabetes mellitus type 2; F, female; FOCF, fibula osteocutaneous flap; FTSG, fullthickness skin graft; LDFF, latissimus dorsi free flap; LFCP, left femoral circumflex perforator; M, male; MDS, Myelodysplastic syndrome; MOF, multi organic failure; MSAP, medial sural artery perforator; RFFF, Radial forearm free flap; SAH, systemic arterial hypertension; SOFF, scapula osteocutaneous free flap; STSG, split-thickness skin graft; TRAM, transverse rectus abdominis musculocutaneous; VIOF, vascularized iliac osteocutaneous flap; VL, vastus lateralis; VRAM, vertical rectus abdominis musculocutaneous.

eschar (-Fig. 4A), ophthalmoplegia, proptosis, left eye vision loss, and cephalea. The CT scan revealed eye involvement and partial infiltration of both maxillas and the left zygomatic bone. Since the extension was large, MRI was performed to assess brain involvement, but it was discarded as it only showed infiltration in the optic nerve. As such, a multidisciplinary team performed a left orbital exenteration, total left and partial right maxillectomy, and a partial ethmoidectomy 

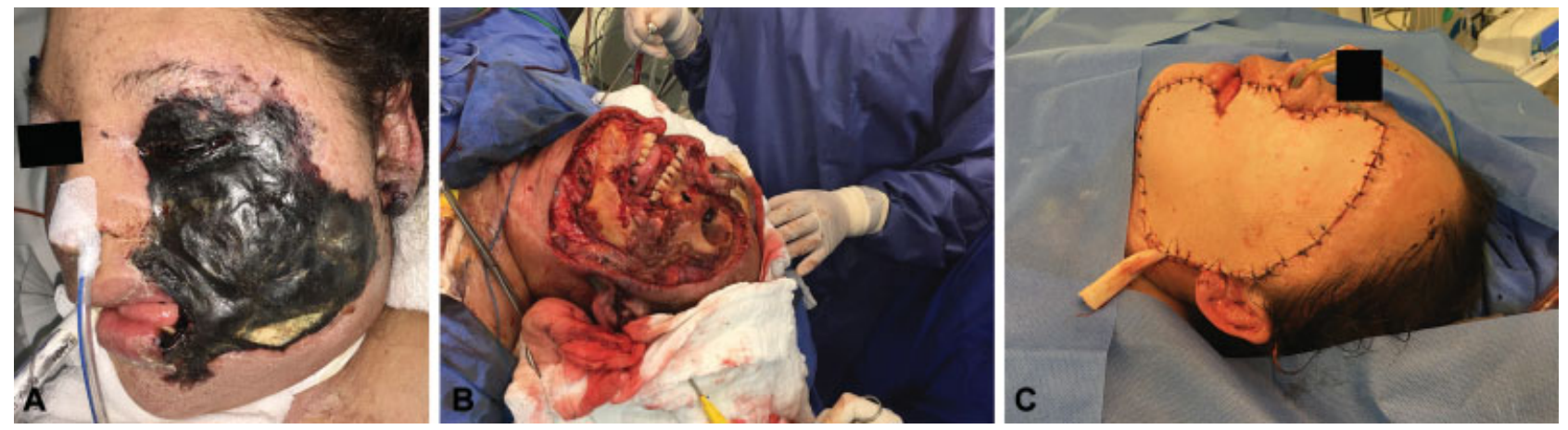

Fig. 2 Case 1: (A) Patient with extensive cutaneous mucormycosis. After complete resection of the affected tissue, performing a left orbital exenteration, resection of the submandibular gland, and left facial muscles (B) were reconstructed with a $22 \mathrm{~cm} \times 16 \mathrm{~cm}$ anterolateral thigh (ALT) flap covering the left hemifacial defect (c).
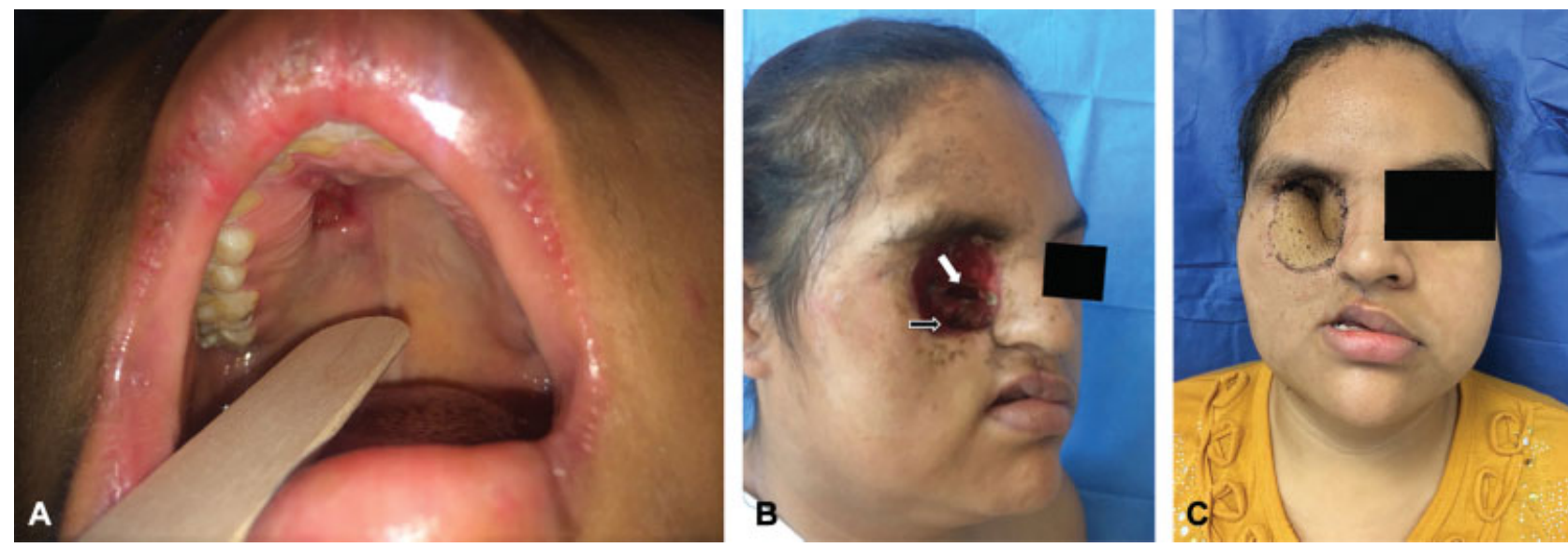

Fig. 3 Case 4: (A) Patient shown preoperatively with the oro-nasal fistula. (B) Posterior to the right orbital exenteration and total maxillectomy, a nasoorbital (solid white arrow) and an oro-antral fistula (hollow white arrow) were presented. (C) One month after reconstruction, the patient was satisfied with the final results although the eye prosthesis is pending.

( - Fig. 4B). Most of the viable skin was spared in addition to a portion of the soft palate. After a negative report for hyphae invasion from the specimen's margins and receptor vessels (temporal vessels), reconstruction was immediately done with an $18 \mathrm{~cm} \times 12 \mathrm{~cm}$ chimeric anterolateral thigh (ALT) with vastus lateralis (VL) flap (-Fig. 4C-E). The patient was admitted to the intensive care unit. The definitive report from the pathologist was a $M$. sp. infection. On the 10th day, the patient presented significant clinical improvement (-Fig. 4F-G). He was discharged in accordance with his wishes and did not present for his follow-up.

In the literature review, we collected 16 cases from 14 different publications, being the first one published from 1999. Reconstruction was made with a free flap (12/16) or pedicled flaps ${ }^{4-7}(4 / 16)$. All of the patients had a head and neck mucormycosis. With respect to all of the cases, 15 were diagnosed as rhinocerebral and one case as cutaneous mucormycosis. ${ }^{6}$ Eleven patients were males and five were females with a mean patient age of 33.0 years. Multiple etiologies were reported, such as diabetes mellitus was the cause in five cases, myelodysplastic malignancies in five cases, trauma in three cases, one case of burn injury, one patient had diabetes mellitus in addition to a myelodysplastic malignancy, and finally, one patient without any etiology. Delayed reconstruction after surgical debridement was employed in most cases (13/16) with an average time of delayed reconstruction of 16.7 weeks (range: 2-36 weeks). Only two authors (3/16) described early or immediate reconstruction., 8

From the cases in our literature review, multiple complications were reported secondary to delayed reconstruction. Among the 13 cases of delayed reconstruction, 9 presented postsurgical complications in which fistula was detected as the most common complication. Three of them were oronasal, ${ }^{7,10,11}$ two were nasoorbital, ${ }^{5,12}$ and one was oropharyngeal..$^{13}$ Moreover, various complications, such as recurrent bleed, ${ }^{12}$ exposed meninges, ${ }^{10}$ cerebrospinal fluid leak, ${ }^{8}$ contractions of anterior neck, ${ }^{14}$ and temporomandibular ankylosis ${ }^{6}$ were reported. In all of these cases, L-AmB was used from the time when the infection was suspected, and in four cases, it was used in conjunction with another antifungal (voriconazole, fluconazole, posaconazole, or tobramycin). ${ }^{11,15-17}$ The followup period presented a mean of 26.3 months (range: 1-72 months).

One study could not be added to our study since it had a lack of patient details and described the use of a chimeric serratus anterior flap with the seventh rib for reconstruction after a maxillectomy. ${ }^{18}$ Besides head and neck reconstructions, other cases of microsurgical reconstruction have been reported in 

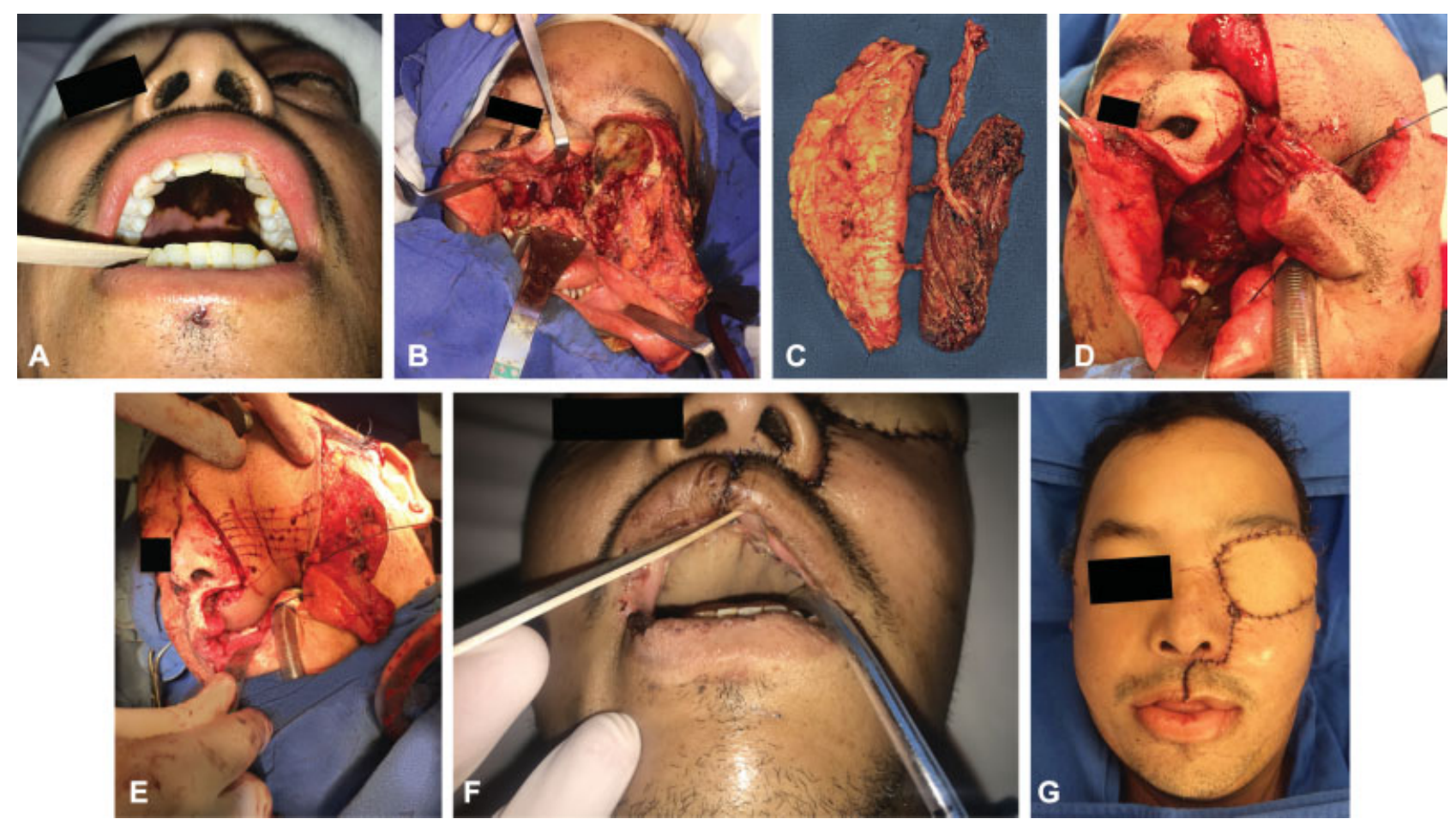

Fig. 4 Case 5: (A) Upon admission, the patient presented with a hard palate necrotic eschar in addition to left eye involvement. (B) Patient after a left orbital exenteration, total left, and partial right maxillectomy, partial ethmoidectomy. (C) The reconstruction was made with a chimeric ALT flap with a portion of vastus lateralis muscle. The descending branch of the circumflex femoral artery entering the vastus lateralis is revealed and giving three cutaneous perforators to the folded skin flap. (D) Here is shown how that distal part of the muscle flap is suspended through a small perforation in the superior roof of the right sinus. (E) The distal portion of the skin flap is sutured to the borders of the oral roof and soft palate, the medial portion of the flap is de-epithelized, and a circular skin island patch was left for adequate closure in the orbital defect. (F, G) After 2 weeks, a satisfactory flap closure in the oral roof was observed in addition to the proper cheek projection despite a total maxillectomy and resection of the base and left lateral nose wall.

patients with mucormycosis. Reinbold et $\mathrm{al}^{19}$ published a report concerning a deep inferior epigastric perforator flap used to cover a patient with an arm amputation and mastectomy. Kyriopoulos et $\mathrm{al}^{20}$ described pedicle latissimus dorsi musculocutaneous and groin flaps for reconstruction of upper extremity burns. Moran et $\mathrm{a}^{21}$ used a latissimus dorsi free flap and an anterolateral thigh (ALT) flap for a patient with upper extremity trauma. Aggarwal and Pennington ${ }^{22}$ used an inferior gluteal artery free flap in addition to two transverse rectus abdominis musculocutaneous (TRAM) flaps for buttocks reconstruction.

\section{Discussion}

The mucormycosis incidence in our hospital is increasing and undoubtedly the determining factor encountered in our patients has been immunosuppression triggered by uncontrolled or complicated diabetes mellitus. The global prevalence of diabetes in adults has increased in the past 30 years, reaching $9.8 \%$ in men and $9.2 \%$ in women since $2008 .^{23}$ Mexico reached an overweight adult population of $71.2 \%$ with a prevalence of diabetes of $14.4 \%$ in 2006 , which is expecting to increase to $22.5 \%$ by $2050 .{ }^{24}$ We do not know precisely how the incidence of mucormycosis has changed over the years or in other parts of the world. However, our theory is that a sustained increase in obesity and diabetes in Mexico is the origin of the growing incidence of mucormycosis; therefore, the necessity for management protocols for these patients exists.

A prompt diagnosis is the most critical aspect of an improved outcome. Most cases (>90\%) are confirmed by the time of the autopsy, and in $81 \%$ of the patients, the autopsy was the only positive diagnostic tool. ${ }^{25}$ It is known that diplopia, ophthalmoplegia, proptosis, ocular pain, periocular cellulitis, acute vision loss, and nasoantral, or cutaneous eschars in a predisposed host carry a potentially high-predictive value. ${ }^{1}$ In a study of 292 cases, it was found that ophthalmoplegia, proptosis, cranial nerve palsy, ocular involvement, peri and orbital cellulitis, and fever appeared to be imminent indications of surgical debridement. ${ }^{26}$ Since antifungal therapy could lead to atypical morphological features, thus reducing the ability to differentiate mucorales from other filamentous fungi, a trained pathologist should examine the specimens, ${ }^{27}$ although a negative biopsy with progressive disease should never delay surgical debridement. For adequate surgical planning, a CT scan is a fundamental tool in early diagnosis of invasive infections, especially when assessing bone involvement. Although a CT scan is not pathognomonic, the absence of one cannot exclude invasion. ${ }^{1,27}$

Along with L-AmB, radical surgical debridement must be expeditious to eradicate the fungal reservoir by acting aggressively until bleeding tissue, bone, and periosteum is wellperfused with the antifungal agent. Because of the invasive and vascular nature of the mucor, it is difficult to deliver the 
antifungal therapy into the hypovascularized tissue. Cosmetic and functional impairment must not be chosen over a complete and adequate surgical excision.

The existing literature reveals contradictory views regarding patient management. When block resections are made, exposed bone and mucosal structures often remain. If these structures are not reconstructed immediately, they will suffer desiccation, and in some cases, even necrosis, leading to atrophy and contraction that will hinder any subsequent reconstructions. Besides, we consider it unnecessary to submit these patients to the visual impact generated by the disfiguring postoperative deformities (-Fig. 5A-E). Moreover, covering the area with a well-vascularized flap facilitates antifungal perfusion to the exposed tissue borders and avoids additional complications, especially fistulas, exposed dura, and secondary wound infections. It could be argued that by doing an immediate reconstruction, a remnant microscopic infection could be missed, thus perpetuating the disease leading to further flap invasion, or even flap loss. Although we do not recommend immediate reconstruction when hemodynamic instability is present (which we found rare in these patients), we recommend it when there is evidence of important cellulitis or aggregated infections, when a complete resection cannot be completed, or intraoperatory biopsy of wound margins and recipient's vessels are not available.
The choice of flap is based on the defects' size. In patients with orbital exenteration, we strongly suggest the use of a medial sural artery perforator (MSAP) flap because of its thin, pliable nature and long pedicle. If orbital coverage is not performed immediately, the tissue can granulate on its own, with the possibility of later covering it with a skin graft. If a maxillectomy is also performed (regardless of an exenteration), an ALT flap reconstruction is ideal because it offers adequate cover to the orbit, cheek skin, and palate besides providing sufficient volume and projection to the malar region. In our opinion, in those cases in which the eye is not preserved, it is unnecessary to reconstruct the defect with an osteocutaneous flap. We recommend focusing on skin coverage and volume. $^{28}$ In larger segments, the defect can be reconstructed using a chimeric ALT flap since this type of flap offers a wide cutaneous island and provides a large volume when accompanied with a vastus lateralis segment. The versatility of this flap is unparalleled since you can design as many skin islands as there are perforators, and it can be used with fascia and a large muscle segment.

When one-third of the palate and nasal floor is affected or oral reconstruction is needed, reconstruction with a facial artery musculomucosal flap is ideal, whereas we suggest the MSAP is used when a greater resection is needed.
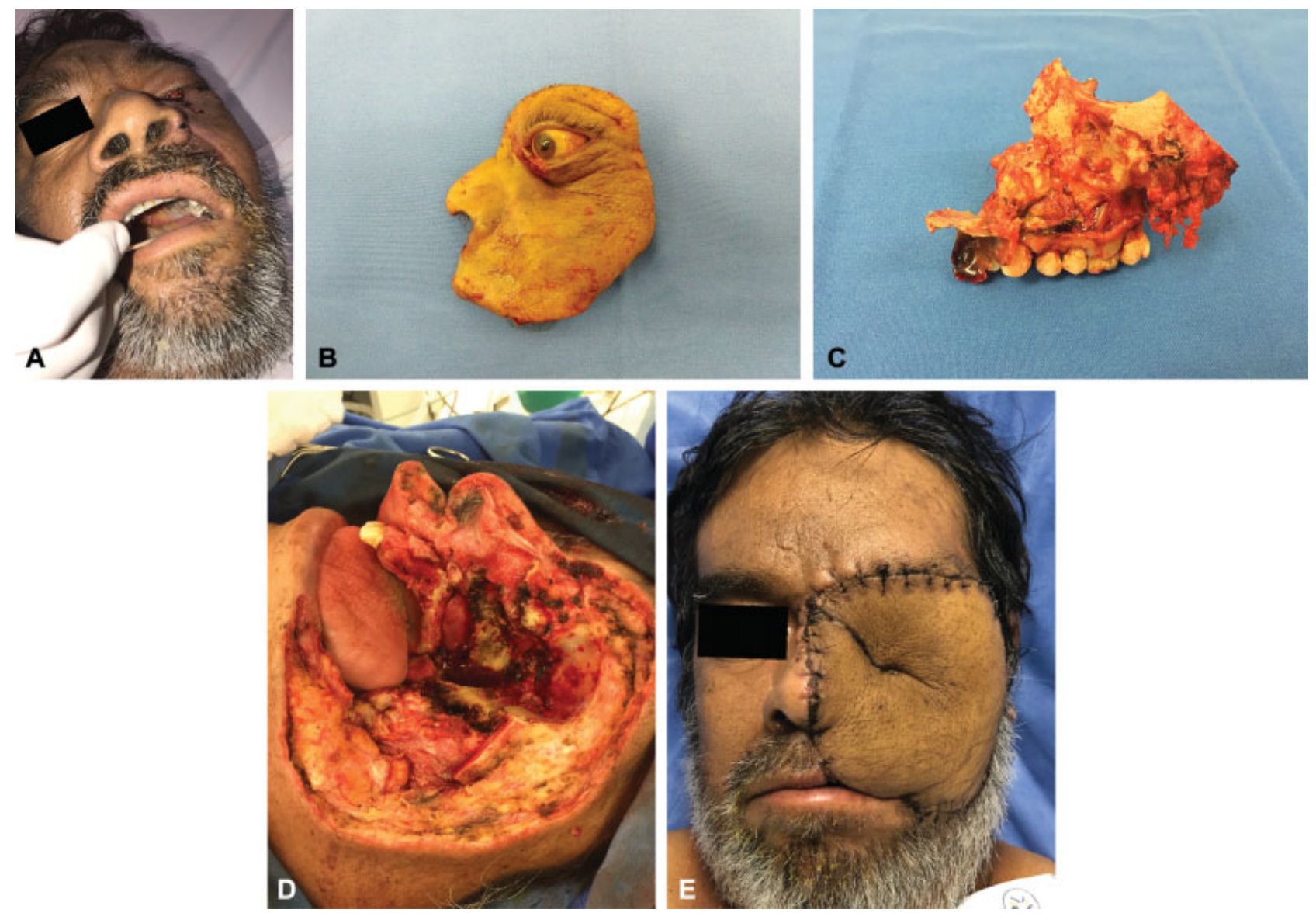

Fig. 5 Case 3: (A) Patient presented with affection of the left eye and hard palate. (B, C) After a complete workup, a left orbital exenteration and total maxillectomy were performed, (D) leaving the patient with disfiguring results and possible surgical comorbidities that were resolved with an immediate reconstruction with a ALT flap leading to acceptable results (E) after three weeks postoperatively. 


\section{Conclusion}

The issue that should be resolved is whether to perform an immediate or delayed reconstruction after complete resection. Thus, multicenter studies are required to determine the impact on these patients. With deep resections, vital tissues are left exposed and, if not covered, could increase these patients' morbidity and mortality. Secondary reconstruction comes together with tissue atrophy and retraction leading to a higher patient disfiguration which produces an impact on the patient and the family. Preventing this type of impact is why we suggest aggressive treatment and always enforce immediate reconstruction, which can be performed safely based on clinical criteria, and after an intraoperative study of wound edges and recipient's vessels, also showing an absence of hyphae invasion.

\section{Conflict of Interest}

None declared.

\section{References}

1 Petrikkos G, Skiada A, Lortholary O, Roilides E, Walsh TJ, Kontoyiannis DP. Epidemiology and clinical manifestations of mucormycosis. Clin Infect Dis 2012;54(June, Suppl. 1):S23-S34

2 Roden MM, Zaoutis TE, Buchanan WL, et al. Epidemiology and outcome of zygomycosis: a review of 929 reported cases. Clin Infect Dis 2005;41(05):634-653

3 Fisher EW, Toma A, Fisher PH, Cheesman AD. Rhinocerebral mucormycosis: use of liposomal amphotericin B. JLaryngol Otol 1991;105(07):575-577

4 Alleyne CH Jr, Vishteh AG, Spetzler RF, Detwiler PW. Long-term survival of a patient with invasive cranial base rhinocerebral mucormycosis treated with combined endovascular, surgical, and medical therapies: case report. Neurosurgery 1999;45(06): 1461-1463, discussion 1463-1464

5 Lari AR, Kanjoor JR, Vulvoda M, Katchy KC, Khan ZU. Orbital reconstruction following sino-nasal mucormycosis. $\mathrm{Br} \mathrm{J}$ Plast Surg 2002;55(01):72-75

6 Tidwell J, Higuera S, Hollier LH Jr. Facial reconstruction after mucormycosis in an immunocompetent host. Am J Otolaryngol 2005;26(05):333-336

7 Herford AS, Tandon R, Pivetti L, Cicciù M. Closure of large palatal defect using a tongue flap. J Craniofac Surg 2013;24(03):875-877

8 Adler N, Seitz IA, Gottlieb LJ. Acute wound closure and reconstruction following head zygomycosis: presentation of two cases and review of literature. J Reconstr Microsurg 2008;24(07):507-513

9 Metzen D, Böhm H, Zimmermann M, Reuther T, Kübler AC, MüllerRichter UDA. Mucormycosis of the head and neck. JCraniomaxillofac Surg 2012;40(08):e321-e327

10 Silberstein E, Krieger Y, Rosenberg N, et al. Facial reconstruction of a mucormycosis survivor by free rectus abdominis muscle flap, tissue expansion, and ocular prosthesis. Ophthal Plast Reconstr Surg 2016;32(06):e131-e132

11 Augustine HFM, White C, Bain J. Aggressive combined medical and surgical management of mucormycosis results in disease eradication in 2 pediatric patients. Plast Surg (Oakv) 2017;25(03): $211-217$
12 Bhatnagar A, Agarwal A. Naso-orbital fistula and socket reconstruction with radial artery forearm flap following orbital mucormycosis. Natl J Maxillofac Surg 2016;7(02):197-200

13 Odessey E, Cohn A, Beaman K, Schechter L. Invasive mucormycosis of the maxillary sinus: extensive destruction with an indolent presentation. Surg Infect (Larchmt) 2008;9(01):91-98

14 Antonetti J, Killyon GW, Chang P, McCauley RL. Microvascular transfer of burned tissue for mandibular reconstruction. JBurn Care Res 2009;30(03):536-539

15 Shand JM, Albrecht RM, Burnett HF III, Miyake A. Invasive fungal infection of the midfacial and orbital complex due to Scedosporium apiospermum and mucormycosis. JOral Maxillofac Surg 2004;62(02):231-234

16 Ojeda-Uribe M, Herbrecht R, Kiefer MH, et al. Lessons from a case of oromandibular mucormycosis treated with surgery and a combination of amphotericin B lipid formulation plus caspofungin. Acta Haematol 2010;124(02):98-102

17 Murphy AD, Williamson PA, Vesely M. Reconstruction of an extensive peri-orbital defect secondary to mucormycosis in a patient with myelodysplasia. J Plast Reconstr Aesthet Surg 2013; 66(03):e69-e71

18 Smith OJ, Pacifico M, Ross GL. Re: 'The rectus sheath and serratus fascia "reverse" fashion flap for the coverage of the lower pole in immediate implant-based breast reconstruction'. J Plast Reconstr Aesthet Surg 2015;68(11):1626-1627

19 Reinbold C, Derder M, Hivelin M, Ozil C, Al Hindi A, Lantieri L. Using free flaps for reconstruction during infections by mucormycosis: A case report and a structured review of the literature. Ann Chir Plast Esthet 2016;61(02):153-161

20 Kyriopoulos EJ, Kyriakopoulos A, Karonidis A, et al. Burn injuries and soft tissue traumas complicated by mucormycosis infection: a report of six cases and review of the literature. Ann Burns Fire Disasters 2015;28(04):280-287

21 Moran SL, Strickland J, Shin AY. Upper-extremity mucormycosis infections in immunocompetent patients. J Hand Surg Am 2006; 31(07):1201-1205

22 Aggarwal S, Pennington D. Reconstruction of gluteal defects using free flaps. J Plast Reconstr Aesthet Surg 2013;66(08):1149-1152

23 Danaei G, Finucane MM, Lu Y, et al; Global Burden of Metabolic Risk Factors of Chronic Diseases Collaborating Group (Blood Glucose). National, regional, and global trends in fasting plasma glucose and diabetes prevalence since 1980: systematic analysis of health examination surveys and epidemiological studies with 370 country-years and $2 \cdot 7$ million participants. Lancet 2011;378 (9785):31-40

24 Meza R, Barrientos-Gutierrez TRojas-Martinez R, et al. Burden of type 2 diabetes in Mexico: past, current and future prevalence and incidence rates. Prev Med 2015;81:445-450

25 Pagano L, Offidani M, Fianchi L, et al; GIMEMA (Gruppo Italiano Malattie EMatologiche dell'Adulto) Infection Program. Mucormycosis in hematologic patients. Haematologica 2004;89(02):207-214

26 Hargrove RN, Wesley RE, Klippenstein KA, Fleming JC, Haik BG. Indications for orbital exenteration in mucormycosis. Ophthal Plast Reconstr Surg 2006;22(04):286-291

27 Walsh TJ, Gamaletsou MN, Mcginnis MR, Hayden RT, Kontoyiannis DP. Early clinical and laboratory diagnosis of invasive pulmonary, extrapulmonary, and disseminated mucormycosis (zygomycosis). 2012;54(Suppl 1):S55-S60

28 Cordeiro PG, Santamaria E. A classification system and algorithm for reconstruction of maxillectomy and midfacial defects. Plast Reconstr Surg 2000;105(07):2331-2346, discussion 2347-2348 